\title{
Infections due to methicillin-resistant strains of Staphylococcus pyogenes
}

\author{
J. W. HARDING \\ From the Department of Pathology, Central Middlesex Hospital
}

SYNOPSIS Two infections due to methicillin-resistant strains of Staph. pyogenes are recorded. Although almost certainly due to the same strain, the infections differed markedly in severity. It iso thought that this discrepancy was due to differences in resistance of the hosts. The epidemiological role of methicillin-resistant staphylococci is discussed, and there is evidence that they may onci occasion produce extremely severe infections.

When methicillin was introduced there was no evidence of resistance to it of Staphylococcus pyogenes (Thompson, Harding, and Simon, 1960). Subsequently, resistant strains were produced in the laboratory (Barber, 1961), and naturally occurring resistance has also been reported (Jevons, 1961: Barber, 1961). Last year a badly injured patient was admitted to this hospital and subsequently suffered from a very severe infection caused by a methicillinresistant strain of Staph. pyogenes; therefore, recent isolations of Staph. pyogenes of the same phage type and sensitivity pattern were tested for methicillin sensitivity, and only one strain was found to be resistant. This organism had been isolated from the wound of another patient, in an adjacent ward, on the same day that the badly injured patient was admitted, and the cases are here recorded.

\section{BACTERIOLOGICAL METHODS}

Sensitivity testing was carried out by the plate-disc method, and when indicated, by the tube dilution technique, the tubes being read after 24 and 48 hours' incubation (Rolinson, 1961).

Phage typing was carried out by the method of Anderson and Williams (1956) using phages supplied by the Staphyloccal Reference Laboratory, Colindale.

Virulence in white mice was assessed by the technique of Selbie and Simon (1952), the inoculum being $0.2 \mathrm{ml}$. of a 1 in 2 suspension of an overnight broth culture of the organism, and the lesion produced being measured on the first, second, third, fourth, and seventh days. Groups of 10 mice were used for each organism studied.

\section{CASE REPORTS}

CASE 1 A railway worker of 28 years was admitted on Received for publication 25 January 1963.
4 September 1962 having been run over by a train. $\mathrm{He}_{\vec{z}}$ was grossly shocked and had a traumatic amputation of the left leg below the knee, a comminuted fracture of the left humerus, a fracture dislocation of the right shoulder, $\vec{\odot}$ and several fractures of the left lower ribs. That evening, $\mathrm{E}$ since 10 pints of blood had failed to reverse shock, a laparotomy was performed and the spleen, which waso found ruptured, was removed. At the same time, thes amputation wound was cleaned up and the fractureso were reduced.

On 5 September a tracheostomy was performed be $\frac{\mathbb{Q}}{2}$ cause of retained chest secretions; the left leg was amputated above the knee and a course of penicillin and streptomycin was started. During the night on 7 September the patient had a rigor and his temperature rose tof $106^{\circ} \mathrm{F}$. Cultures of the blood and sputum taken on 8 . September both yielded Staph. pyogenes. He was treated with penicillin, 2 mega units two-hourly, streptomycin 0.5 g. b.d., and methicillin, 1 g. six-hourly. On 11 Sep? tember treatment was changed to methicillin, $2 \mathrm{~g}$. four hourly, and the organism was tested for sensitivity tof this compound. On 12 September the intracaval drip was removed, and Staph. pyogenes was grown from the tips of the tube. On this day disc sensitivity tests showed weak resistance to methicillin, and on 13 Septembe? tube sensitivity tests confirmed slight resistance to methicillin. Since the patient seemed rather better thats day, treatment was continued.

On 14 September, however, there was no improvement ${ }_{N}$ and further incubation of the tube sensitivity tests had shown that some of the organisms were markedly resistan to methicillin. Treatment was, therefore, changed too chloramphenicol, $0.5 \mathrm{~g}$. six-hourly, and erythromycin $600 \mathrm{~g}$. four-hourly, with a good response. In four dayș? the temperature fell from $102^{\circ}$ to almost normal; the chest cleared, and on 20 September the dose of chlor $\overrightarrow{0}$ amphenicol was halved. Antibiotics were discontinued or 30 September, and the patient made a steady recovery. $\frac{?}{\mathbb{D}}$

Bacteriology All strains of Staph. pyogenes wer尺 resistant to penicillin, streptomycin, tetracycline, phen? 
ethicillin, ampicillin, methicillin, and Cloxacillin, and sensitive to chloramphenicol, erthyromycin, novobiocin, vancomycin, ristocetin, and fucidin. The growth of the organisms was inhibited in tubes by methicillin at a concentration of $8 \mu \mathrm{g} . / \mathrm{ml}$. after 24 hours' incubation and at $60 \mu \mathrm{g}$. $/ \mathrm{ml}$. after 48 hours' incubation. The corresponding concentrations of cloxacillin were $0.5 \mu \mathrm{g} . / \mathrm{ml}$. and $4 \mu \mathrm{g} . / \mathrm{ml}$. No evidence of methicillin destruction by the organisms could be shown.

The phage-types were for sputum $7 / 47 / 53 / 54 / 77$, for blood $7 / 42 \mathrm{E} / 53 / 54 / 75 / 77$, and for the intravenous catheter $7 / 47 / 53 / 54 / 75 / 77$.

CASE 2 A woman aged 47 underwent arthrodesis of the hip on 27 August 1962. A haematoma in the wound became infected. On 4 September sutures were removed, and there was considerable discharge from the wound. Culture yielded Staph. pyogenes. The organism persisted despite a course of chloramphenicol, and the wound healed slowly. The patient was transferred for convalescence on 6 October, with a small sinus at the site of infection but without the result of the operation being impaired.

Bacteriology The organism was resistant to penicillin, streptomycin, tetracycline, phenethicillin, ampicillin, methicillin, and Cloxacillin, and sensitive to chloramphenicol, erythromycin, novobiocin, vancomycin, ristocetin, and fucidin. Tube sensitivity test results to methicillin and cloxacillin were identical to those of the other strain. The phage type was $7 / 42 \mathrm{E} / 53 / 54 / 75 / 77$.

\section{VIRULENCE TESTS IN MICE}

The strains of Staph. pyogenes from these two patients were compared with each other and a third strain recently isolated from a patient with a wound infection by inoculation into the thighs of mice. The third strain of Staph. pyogenes showed the same sensitivity pattern against penicillin, streptomycin, chloramphenicol, tetracycline, and erythromycin and was of the same phage type as the strains from the two patients, but differed in being methicillinsensitive.

The results of these virulence tests, shown in the table, failed to show any significant difference between the three strains.

\section{T A B L E}

RESULTS OF VIRULENCE TESTS IN MICE

\begin{tabular}{llllll}
$\begin{array}{l}\text { Strain of Staph. } \\
\text { pyogenes }\end{array}$ & \multicolumn{6}{l}{$\begin{array}{l}\text { Average } \\
(\mathrm{mm} .)\end{array}$} & \begin{tabular}{l} 
Diameter of Swelling of Thigh \\
\cline { 2 - 6 }
\end{tabular} & Day 1 & Day 2 & Day 3 & Day 4 & Day 7 \\
\hline First patient & 2.9 & 3.4 & 3.9 & 4.2 & 4.0 \\
$\begin{array}{l}\text { Second patient } \\
\text { Methicillin-sensitive } \\
\text { strain }\end{array}$ & 3.0 & 3.5 & 4.1 & 4.1 & 4.0 \\
& 3.0 & 3.7 & 4.1 & 4.0 & 3.9
\end{tabular}

\section{DISCUSSION}

The appearance within four days of two strains of Staph. pyogenes with identical antibiograms, identical phage types, and both resistant to methicillin is unlikely to be coincidental. It is therefore accepted that cross-infection occurred. Efforts to trace the vehicle of cross-infection were unsuccessful. The only members of staff who had access to both patients were medical and they were on holiday at the time that it became evident that cross-infection had occurred. Nasal swabbing performed after their holidays was negative.

Methicillin-resistant strains of Staph. pyogenes are still rare (Knox, 1961) and the strains isolated in this instance are similar to those previously reported. They do not destroy methicillin; they belong to phage group III (Jevons, 1961; Barber, 1961), and only a small proportion of the organisms have a high degree of resistance to methicillin (Rolinson, 1961). There was no history of previous contact of either of the patients with methicillin, and any such contact was extremely unlikely.

The magnitude of infection between the two patients differed markedly. The first patient suffered from a severe pneumonia and septicaemia, whereas the second patient had a comparatively mild though persistent infection. If, as is postulated, the two infections were due to the same strain, the differences in the lesions produced in the two patients cannot be explained by a difference in the virulence of the organism, and must therefore be ascribed to differences in the resistance of the two hosts. This can be correlated with shock and multiple traumata of the first patient compared with the relatively good condition of the second patient. This hypothesis is in keeping with the results of virulence tests in mice comparing the two strains of Staph. pyogenes for the two patients.

Methicillin-resistant staphylococci do not destroy methicillin. Knox and Smith (1961) suggested that they resemble those penicillin-resistant staphylococci which do not produce penicillinase more closely than those strains which do produce penicillinase. The only type of penicillin resistance which is thought to be of serious clinical importance is due to penicillinase-producing strains (Knox and Smith, 1961), and therefore the clinical importance of methicillin-resistant strains is uncertain. A strain of Staph. pyogenes similar to those isolated from the two patients, except that it was methicillinsensitive, failed to show any significant difference in virulence in mice from the methicillin-resistant strains. Admittedly, no parallelism can be assumed in virulence of different strains between mice and humans, but it is possible that methicillin-resistant 
strains are not necessarily so unimportant as has hitherto been hoped. The first patient described shows without doubt that in debilitated patients very severe infection can be caused by methicillinresistant strains of Staph. pyogenes.

I would like to thank Mr. J. G. Bonnin and Mr. T. G. I. James for permission to publish details of cases under their care, and Dr. O. P. W. Robinson of Beecham Research Laboratories for supplies of Cloxacillin.
REFERENCES

Anderson, E. S., and Williams, R. E. O. (1956). J. clin. Path., 9, 94.음 Barber, M. (1961). Ibid., 14, 385.

Jevons, M. Patricia (1961). Brit. med. J., 1, 124.

Knox, R. (1961). Ibid., 1, 126.

- and Smith, J. T. (1961). Lancet, 2, 520.

Rolinson, G. N. (1961). Brit. med. J., 1, 125.

Selbie, F. R., and Simon, Rosemary D. (1952). Brit. J. exp. Path., 33,

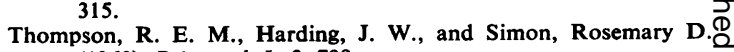
(1960). Brit. med. J., 2, 708. 